ADENSAMENTO POPULACIO

$$
\begin{array}{r}
\text { INTERAÇÃO E CONFLITC } \\
\text { AMAZÔNIA CENT }
\end{array}
$$




\section{O ANO 1000: ADENSAMENTO POPULACIONAL, INTERAÇÃO E CONFLITO NA AMAZÔNIA CENTRAL}

\section{CLAIDE DE PAULA MORAES}




\title{
O ANO 1000: ADENSAMENTO POPULACIONAL, INTERAÇÃO E CONFLITO NA AMAZÔNIA CENTRAL
}

\section{Resumo}

Buscamos nesse trabalho apresentar dados de pesquisas desenvolvidas na região do baixo rio Madeira e médio rio Amazonas que possam mostrar evidências de uma história de ocupação de longa duração, com grande adensamento populacional na região por volta do ano mil da era Cristã. $\mathrm{Na}$ fase Paredão (séculos VII a XII) é possível perceber um rápido crescimento populacional comparando o registro dos sítios mais antigos e os mais tardios da ocupação. Por volta do século IX DC aparecem na região as ocupações com cerâmicas polícromas da fase Guarita. Discutiremos a ocupação Guarita e as relações com grupos já estabelecidos na região desde o início da era Cristã (fases Axinim e Paredão), e a consequente emergência de conflitos visualizados através do registro arqueológico.

Palavras-chave: Amazônia Central, adensamento populacional, conflito.

\section{THE FIRST MILLENNIUM AD: POPULATION GROWTH, INTERACTION, AND CONFLICT IN THE CENTRAL AMAZON}

\begin{abstract}
This article brings evidence of a long-term history of occupation of the lower Madeira and Middle Amazon rivers that culminated with large population aggregates around $\mathrm{AD}$ 1,000. A comparison between early and late Paredão phase (VII to XII centuries AD) shows a process of population growth. From ca. AD 900 onwards there is a growing presence of occupations associated with Guarita phase polychrome ceramics. This article presents data on the Guarita phase occupations and the kind of links these newcomers established with the groups already settled in the area (Axinim and Paredão phases), with strong evidence for conflict, which can be inferred from the archaeological record.
\end{abstract}

Keywords: Central Amazon, population growth, conflict. 


\section{L'AN 1000: AUGMENTATION DE LA POPULATION, INTERACTION ET CONFLIT DANS L'AMAZONIE CENTRALE}

\section{Résumé}

Dans cet article nous cherchons à présenter des données de recherche obtenues pour le bas Madeira et le Moyen Amazone qui puissent evidencier l'histoire de l'occupation à long terme, où on retrouve une forte densité de la population dans la région autour de l'an mille de l'ère chrétienne. Pendant la phase Paredão (entre les siècles VII à XII), nous pouvons voir une augmentation rapide du peuplement en comparant les données des sites plus anciens avec celles des sites de la fin de la période. Autour du IXème siècle il apparait dans la région des occupations ayant de la céramique polychrome de la phase Guarita. Nous discuterons cette occupation Guarita et sa relation avec les groupes plus anciens, établis dans la région depuis le début de l'ère chrétienne (les phases Axinim et Paredão), et par conséquent l'émergence des conflits vus à travers le registre archéologique.

Mots-Clés: Amazonie Centrale, augmentation de la population, conflit. 


\section{INTRODUÇÃO}

Os avanços realizados nos últimos anos em pesquisas arqueológicas na bacia Amazônica têm permitido a elaboração de um quadro mais complexo sobre a ocupação antiga da região, que tem como foco menos a classificação tipológica das sociedades pré-coloniais em categorias genéricas e mais o entendimento das diversas e distintas histórias de seus antigos habitantes. Neste artigo procuraremos mostrar que, à variabilidade verificada no registro arqueológico, tradicionalmente expressa em categorias classificatórias como "fases" e "tradições" definidas com base na análise cerâmica, correspondem também padrões distintos de organização social e política.

O foco principal desse artigo é o período mais tardio da ocupação dos grupos produtores das cerâmicas da tradição Borda Incisa representados, na Amazônia Central (Figura 1) pelas ocupações associadas à fase Paredão (séculos VII a XII DC), e no baixo rio Madeira pelas ocupações associadas à fase Axinim (séculos I a XIII DC). Nosso propósito é entender as relações dessas ocupações entre si e com a ocupação de povos produtores de cerâmica da tradição Polícroma, de ampla dispersão regional e que na Amazônia Ocidental está principalmente representada por ocupações associadas à fase Guarita. Nossa hipótese é que a transição das ocupações da tradição Borda Incisa às ocupações da tradição Polícroma foi um processo conflituoso, marcado pela guerra, e cujas evidências podem ser verificadas pela construção de estruturas defensivas, como valas e paliçadas, escavadas em sítios da região.

\section{HISTÓRICO DE PESQUISAS RECENTES NO MÉDIO RIO AMAZONAS E MÉDIO/BAIXO RIO MADEIRA}

Apesar de iniciativas pioneiras no século XIX, pesquisas arqueológicas sistemáticas no médio Amazonas (Solimões) tiveram início nos anos 1950 com os trabalhos de Peter Hilbert (1968). Os trabalhos de Hilbert buscavam dar subsídios às hipóteses de Meggers e Evans (1957) sobre uma possível rota de entrada dos povos produtores da cerâmica da tradição Polícroma na Amazônia desde os Andes através do rio Solimões. Dentro da mesma perspectiva, Simões (1974) realizou levantamentos e identificação de sítios arqueológicos no baixo rio Negro. Os trabalhos de Hilbert foram revisados por Lathrap (1970), Brochado (1984), Lathrap e Oliver (1987). Tais revisões criaram algumas das hipóteses mais importantes para a interpretação da história de ocupação das terras baixas da América do Sul, conhecidas genericamente como "modelo cardíaco" (Carneiro 1971, Heckenberger et al. 1998), que, de maneira oposta às formulações de Meggers (1954; 1971; 1990) e Meggers e Evans (1983), propôs que a Amazônia central teria sido uma área de longa e contínua ocupação humana desde o início do Holoceno.

Em meados dos anos 90 a arqueologia no estado do Amazonas foi retomada com o desenvolvimento do Projeto 
Amazônia Central (PAC), que tinha como um de seus objetivos principais testar as hipóteses de Lathrap e seus alunos. A descoberta de grandes sítios nas proximidades de Manaus colocou a região no debate sobre a estrutura e funcionamento das sociedades hierarquizadas na Amazônia antiga (Neves \& Petersen 2006). Desde então, uma série de trabalhos foram produzidos refinando muito os dados sobre cronologia, classificação, densidade demográfica, organização social e política, modificações antrópicas da paisagem, contextos funerários, guerra e forma de assentamentos (Heckenberger et al. 1998; 1999; Petersen et al. 2001; Neves et al. 2003, 2004; Machado 2005; Lima et al. 2006; Moraes 2006, 2010; Rebellato 2007; Chirinos 2007; Lima 2008, 2010; Neves 2008, 2010; Arroyo-Kalin 2008, Rapp Py-Daniel 2009, 2010, entre outros).

As pesquisas arqueológicas na região do baixo rio Madeira tiveram início nos anos 1920, com Curt Nimuendajú que, motivado pelos achados de Barbosa Rodrigues no Baixo Amazonas (cemitério de Miracanguera), veio para a região em busca de materiais para o Museu de Göteborg, na Suécia. Porém, apesar do grandioso trabalho desenvolvido por Nimuendajú na região do rio Madeira, publicados postumamente (Nimuendajú 2004), a leitura de seus relatórios mostra certo desapontamento com a "pobreza" dos achados da região.

"Contrary to my expectations, the finds on the Rio Madeira were extraordinarily scarce, which may in part have been due to the fact that most of the terras pretas were inaccessible for investigations. At Bor-

ba, I heard about burial urns which were said to have been found in a suburb called Colonial. This was, however, too vague to be relied upon, had not the whole story originated from the following find" (Nimuendajú 2004:159).

Os trabalhos no baixo rio Madeira foram posteriormente retomados por Miller, que em 1979 estendeu suas pesquisas desde Rondônia, onde anteriormente trabalhava, ao Amazonas (Miller 2010, com. pessoal). Conforme consta no Cadastro Nacional de Sítios Arqueológicos do IPHAN, foram identificados 23 sítios arqueológicos. Os trabalhos foram desenvolvidos nos rios Madeira, Marmelos, Ipixúna e Uruapiára. Em 1981, Mario Simões e Daniel Lopes identificaram e escavaram 31 sítios entre as regiões de Manicoré e a foz do rio Madeira (Simões \& Lopes 1987). Os pesquisadores definiram três fases arqueológicas: Borba, Axinim e Curralinho. A fase Borba foi atribuída à sub-tradição Guarita da tradição Polícroma e as fases Axinim e Curralinho foram associadas à tradição Inciso Ponteada.

Em 2005, Raoni Valle realizou um levantamento em áreas indígenas do município de Autazes e identificou 10 sítios arqueológicos. Em 2007, Raoni Valle e Claide Moraes compuseram parte de uma equipe multidisciplinar que buscava coletar dados para colaborar na elaboração do plano de manejo de unidades de conservação na bacia do rio Aripuanã. No médio rio Aripuanã foram identificados 14 sítios arqueológicos. 
Em 2010 Moraes realizou uma etapa de levantamento no rio Madeira entre a foz do rio Machado e a divisa entre os municípios de Borba e Nova Olinda, como parte de um levantamento arqueológico em todo o trecho do rio Madeira no estado do Amazonas que inclui a reidentificação dos sítios trabalhados por Simões e Lopes em 1981 (Simões \& Lopes 1987).

O resultado foi a reidentificação de sítios trabalhados por Curt Nimuendajú, Eurico Miller, Mário Simões e Daniel Lopes, e visitados por Fraser (2009), Junqueira (2008) e Kawa (2008), além da identificação de novos pontos, totalizando 129 sítios arqueológicos na região pesquisada (Figura 1).

\section{CRONOLOGIA E CARACTERIZAÇÃO DAS OCUPAÇÕES}

A ocupação humana da Amazônia central se iniciou há pelo menos 8.500 anos, conforme as datas obtidas na escavação do sítio Dona Stella, localizado em uma campinarana situada entre os rios Negro e Solimões (Costa 2009).

Na região do rio Madeira, trabalhos ainda inéditos de Eurico Miller por ocasião do PRONAPABA identificaram sítios pré-cerâmicos datados por volta de 7.000 AP (Miller 2010, com. pessoal). Recentemente tivemos acesso a esses dados inéditos, gentilmente cedidos por Miller, e verificamos que, além dos contextos pré-cerâmicos, as pesquisas do PRONAPABA (Miller 1979/1983) identificaram também sítios de ocupações ceramistas com datas que recuam pelo menos até 5.200 anos. Como o próprio Miller alerta (2010, com. pessoal), até que novos trabalhos sejam desenvolvidos nesses sítios, essas datas devem ser vistas com ressalvas, mas ao que tudo indica os principais problemas podem estar ligados à associação e contextualização cultural dos materiais. Em outras áreas da Amazônia, como a confluência dos rios Negro e Solimões, o médio rio Caquetá e a região do baixo Tapajós, as evidências de ocupação humana no Holoceno médio são mais escassas, quando não inexistentes (Neves 2011).

De acordo com os dados de Miller, as ocupações ceramistas do Holoceno médio estão presentes em vários sítios (Figura 2). Se considerarmos os dados isolados do trabalho de Miller temos um pequeno hiato entre as ocupações ceramistas mais antigas e o período pré-cerâmico. Como aponta Miller (2010, com. pessoal), a continuidade das pesquisas poderá mudar significativamente os dados superficiais produzidos na primeira exploração. Nesse caso, o hiato observado pode ser apenas a falta de uma cronologia melhor estabelecida.

De qualquer forma, se considerarmos os dados em uma escala regional mais ampla, o hiato desaparece. As ocupações ceramistas com datas por volta de 5 mil anos são contemporâneas às datas mais recentes para os sítios précerâmicos da Amazônia Central.

Os dados produzidos nos últimos anos no médio e no baixo rio Amazonas e mais recentemente no baixo rio Madeira vêm mostrando um quadro bastante interessante para entender a arqueologia da 


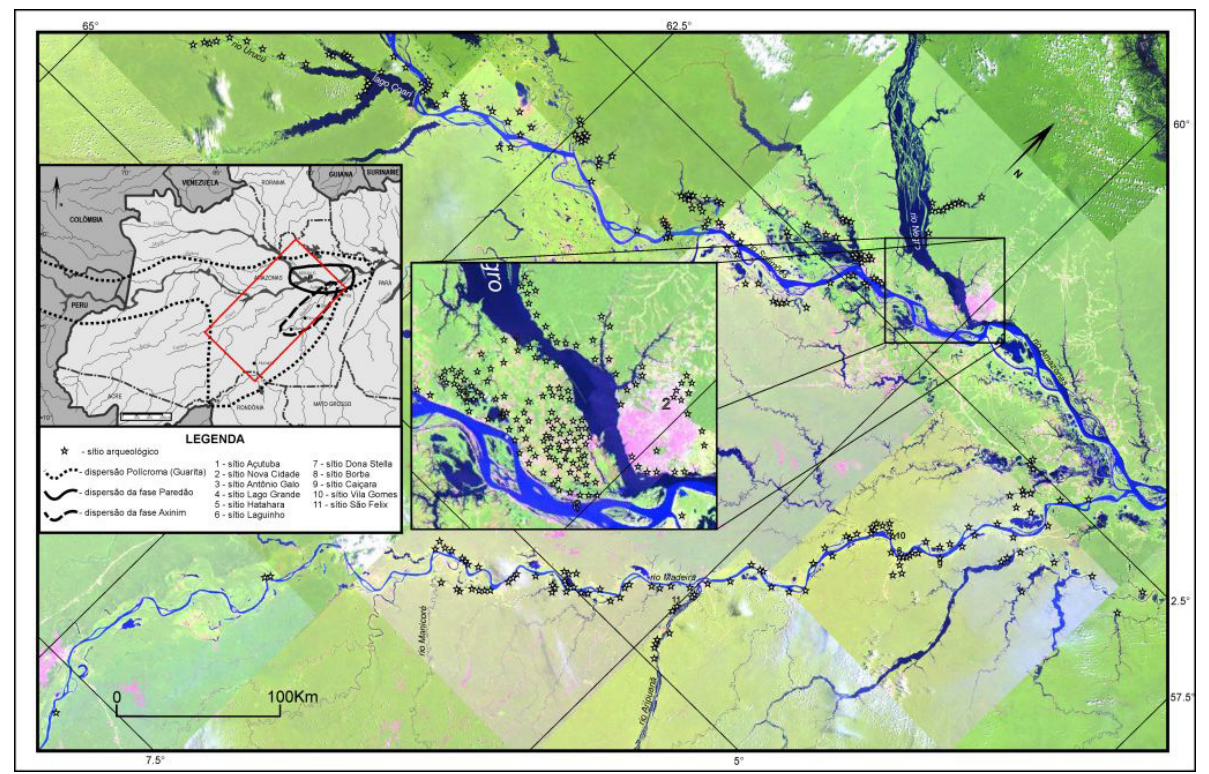

Figura 1 - Sítios arqueológicos pesquisados pelo Projeto Amazônia Central (378 sítios). Mapa de Claide Moraes, imagem Land Sat (Fonte: http:/ /glovis.usgs.gov).

região. No século XVI DC a calha do rio Amazonas e alguns de seus principais afluentes, desde o Peru, Equador e Colômbia até a foz do rio Madeira, era ocupada por grupos que produziam cerâmicas atualmente associadas à tradição Polícroma. Esse processo de ocupação se iniciou no final do primeiro milênio DC e tem um padrão cronológico claro que mostra que as datas mais antigas estão na Amazônia central e na bacia do Madeira, enquanto que as mais recentes estão no alto Amazonas. De qualquer modo, sob o ponto de vista do registro arqueológico, a distribuição de sítios da tradição Polícroma promoveu uma espécie de padronização do registro arqueológico de partes da Amazônia ocidental no início do segundo milênio DC.

Sítios multicomponenciais são comuns ao longo das várzeas do rio Solimões e do rio Madeira. Nesses sítios, sob as camadas superficiais, normalmente associadas às ocupações da tradição Polícroma, encontram-se enterradas camadas com cerâmicas relativamente distintas entre si, quando comparadas em uma perspectiva regional. São cerâmicas tais como Pocó, na região do rio Trombetas (Hilbert 1955, Hilbert \& Hilbert 1980 e Guapindaia 2008) ${ }^{1}$, Açutuba, Manacapuru e Paredão (Hilbert 1968 e Lima et al. 2006) nas proximidades de Manaus, Caiambé nas proximidades de Tefé (Hilbert 1968 e Costa 2011) e Axinim, no baixo rio Madeira (Simões \& Lopes 1987). Tais complexos antigos, por sua vez, foram agrupados em uma tradição com ampla distribuição geográfica e duração cronológica, conhecida como tradição Borda Incisa (Meggers \& Evans 1961) ou Barrancóide da Amazônia (Hecken- 


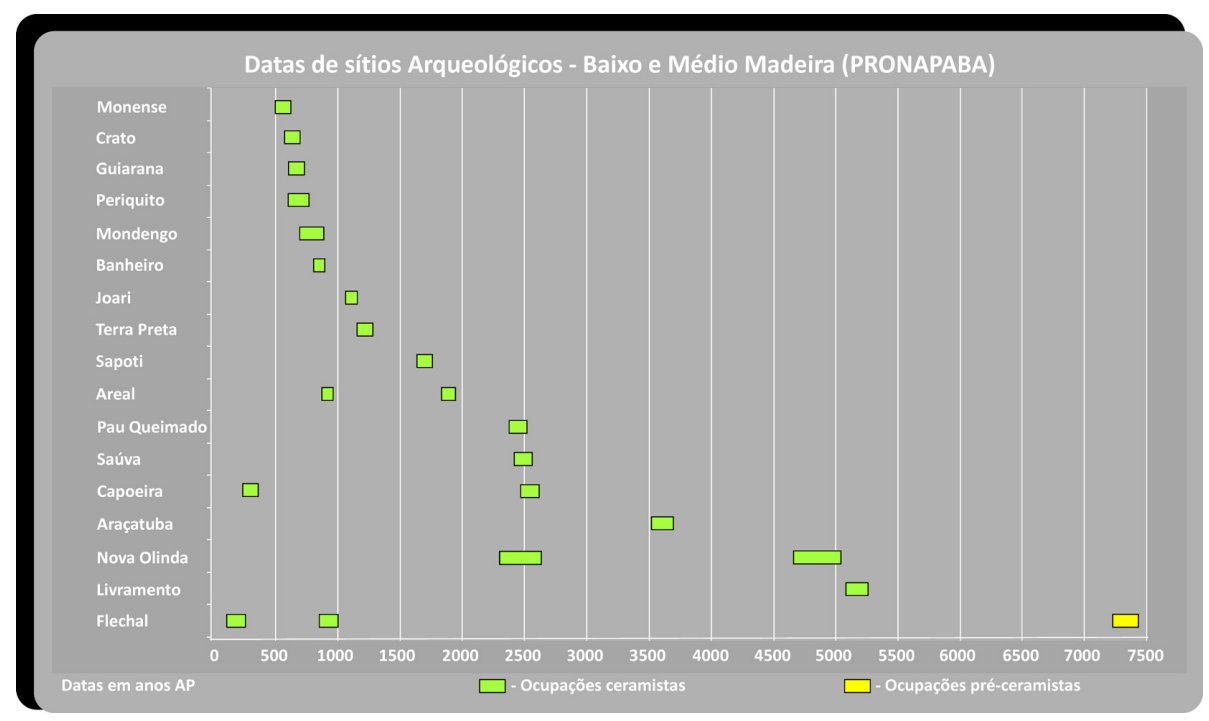

Figura 2 - Cronologia dos sítios pesquisados por Eurico Miller no estado do Amazonas, rio Madeira, durante o PRONAPABA (Dados inéditos cedidos por Eurico Miller).

berger et al. 1998 e Lima 2008).

Como bem apontou Lima (2008), as cerâmicas das ocupações anteriores às ocupações polícromas carregam várias semelhanças com as cerâmicas das séries Saladóide e Barrancóide do norte da América do Sul. Para Heckenberger (2005) essas características comuns vistas nas cerâmicas exemplificariam a ocorrência de uma grande dispersão de grupos falantes de línguas da família Arawak.

$\mathrm{Na}$ região pesquisada, a cronologia inclui os seguintes componentes: fase Açutuba (século III AC - IV DC), fase Axinim (séculos I a XIII), fase Manacapuru (séculos IV a VIII DC), fase Paredão (séculos VII e XII DC) e fase Guarita (séculos IX-XVI DC).

De maneira sintética, as características do material das diferentes fases são:

Fase Açutuba - Ocorrência de caraipé adicionado à pasta de argila, predominância de formas irrestritivas, decoração variada com motivos incisos curvilíneos, excisões sobre engobo vermelho, acanalados, apêndices zoomorfos, flanges labiais, flanges mesiais, engobo branco e pintura policrômica (Lima 2008). São marcantes as semelhanças com as cerâmicas da fase Pocó do baixo rio Trombetas (Guapindaia 2008, Hilbert \& Hilbert 1981, Lima et al. 2006)

Fase Axinim - Tem muitas semelhanças com a fase Paredão. As bordas com dupla incisão são muito próximas do que classificamos como fase Manacapuru. O estilo "barroco" visto nas cerâmicas das fases Konduri e Tapajônica está também representado. Tecnologias sofisticadas de decoração com o uso de incisões e excisões para contrastar campos de cores diferentes em superfícies engobadas, freqüentemente 
vistos na cerâmica Marajoara, estão também representados como no vaso 48 da Figura 3. As cerâmicas do conjunto Axinim encontradas no baixo rio Madeira são bastante singulares, inserilas em um dos complexos cerâmicos pré-definidos para a Amazônia é tarefa muito difícil. Porém, na singularidade desse conjunto está também representada a pluralidade regional da ocupação pré-colonial amazônica. De qualquer modo, o material da fase Axinim não cabe dentro da tradição Inciso e Ponteada, conforme proposto inicialmente por Simões e Lopes (1987).

Fase Manacapuru - Ocorrência principalmente de cauixí adicionado à pasta de argila, predominância de formas restritivas, decoração variada com incisões retilíneas duplas, ponteado, apêndices zoomorfos, flanges labiais e engobo vermelho (Lima 2008).

Fase Paredão - Predominância de cauixí adicionado à pasta de argila, vasos com paredes muito finas e bem queimadas, presença de vasos com alças, vasos com pedestais, decoração com incisões em linhas finas, pintura também em linhas muito finas, engobo vermelho e apliques antropomorfos estilizados (as cabecinhas Paredão) associados às urnas funerárias (Hilbert 1968 e Moraes 2006).

Fase Guarita - Predominância de caraipé adicionado à pasta de argila, ocorrência de vasos com borda reforçada, decoração policrômica com motivos geométricos (faixas grossas e linhas finas), decoração plástica acanalada, urnas funerárias antropomorfas, vasos com flange mesial, ocorrência de engobo branco e vermelho.

\section{OS DADOS ARQUEOLÓGICOS}

No médio e baixo rio Madeira, desconsiderando as cerâmicas antigas encontradas por Miller que ainda não foram estudadas, os contextos mais antigos de presença de cerâmica datam do início da era Cristã. Esses conjuntos foram classificados por Simões e Lopes (1981) como pertencentes à fase Axinim, associada à tradição Inciso Ponteada, mas análises posteriores do material mostram semelhanças muito maiores com as cerâmicas da tradição Borda Incisa, tanto na forma como na decoração (Figura 3).

Há um consenso entre autores que propõem uma correlação entre sítios com cerâmicas da tradição Borda Incisa e ocupações de povos falantes de línguas Arawak (Heckenberger 2002; Lathrap 1970; Lima 2008; Moraes 2006, 2010). Para as ocupações apresentando cerâmicas polícromas Guarita, nossa hipótese (Moraes 2006, 2010; Neves 2010) é que, pelo menos no início do segundo milênio DC, sejam manifestações de grupos falantes de línguas do tronco Tupi que expandiram-se pela Amazônia Ocidental a partir da bacia do alto rio Madeira.

Por volta do século VII da era Cristã surgem, no registro arqueológico da região, ocupações de sítios associados à fase Paredão. Além de uma definição muito precisa do conjunto cerâmico pertencente a esses sítios, é possível identificar, em vários deles, concentrações de vestígios que apontam para ocupações em aldeias circulares, com a construção de casas em plataformas artificiais, denominadas "montículos" (Donatti 2003; 


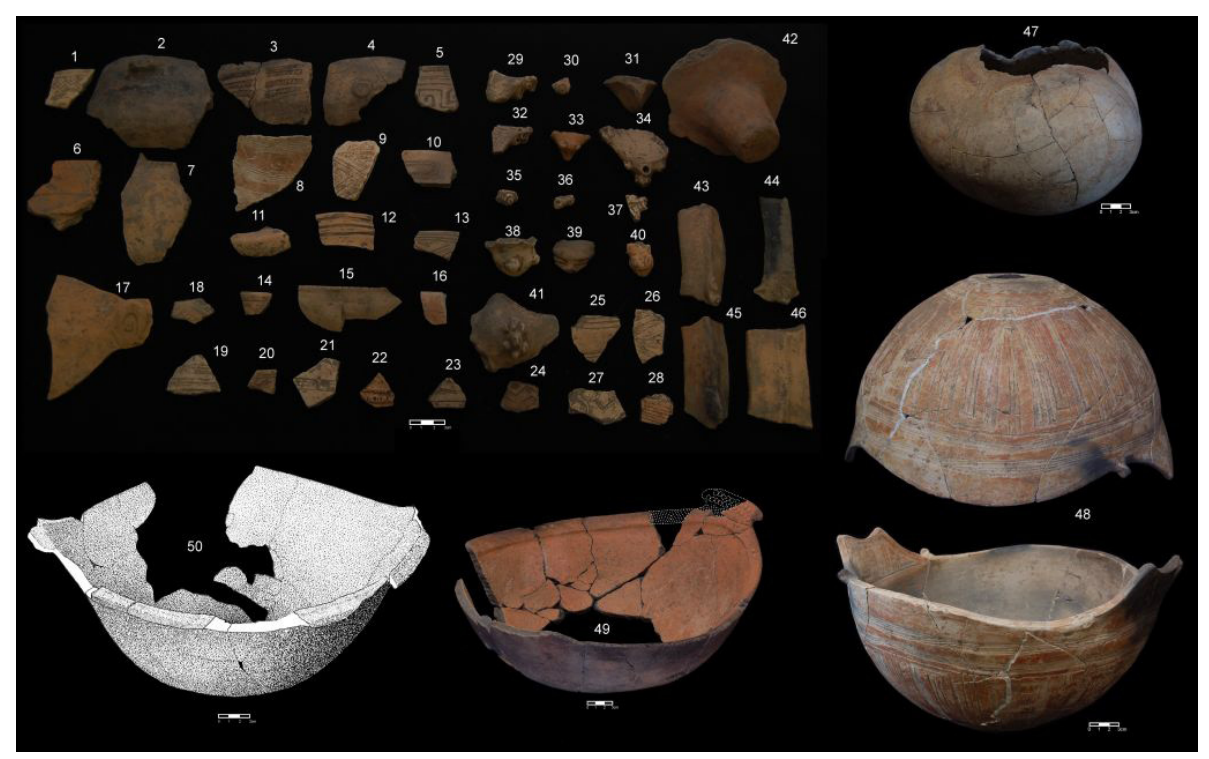

Figura 3 - 1 a 48, cerâmica da fase Axinim, sítio VilaGomes (1 - 16: bordas; 17 - 28: paredes decoradas; 29 a 41: apliques modelados; 42: pé de vaso trípode; 43-46 fragmentos de alças, 47: vaso com decoração incisa e pintura vermelha apresentando 3 protuberâncias no bojo (provável acompanhamento funerário), 48: vaso zoomorfo em forma de canoa apresentando apliques modelados, engobo vermelho e posterior decoração incisa contrastando tonalidades de cores dos campos decorativos (provável acompanhamento funerário); 49: vaso da fase Paredão, sítio Antônio Galo, apresentando forma de canoa, decoração incisa e pequenas bolinhas aplicadas; 50: vaso da fase Manacapuru, sítio Hatahara, apresentando também forma de canoa e decoração incisa na borda (utilizado como tampa para urna funerária). Fotomontagem de Claide Moraes; fotos dos fragmentos: Edvaldo Pereira; fotos dos vasos: Claide Moraes; desenho em pontilhismo: Val Moraes.

Moraes 2006, 2010; Rebellato 2007). Ao menos no período mais tardio das ocupações da fase Paredão os indivíduos foram sepultados nessas mesmas plataformas, provavelmente enterrados dentro das casas (Rapp Py-Daniel 2009, 2010). São comuns também sepultamentos em urnas cerâmicas piriformes decoradas com apêndices laterais modelados antropomorfos e zoomorfos (Hilbert 1968).

As ocupações Paredão mais antigas parecem ter sido aldeamentos pequenos como demonstra o conjunto de montículos de uma parte do sítio An- tônio Galo, localizado na área de confluência dos rios Negro e Solimões, que foi objeto de escavações extensas (Moraes 2006, 2010). A aldeia circular identificada no sítio apresenta 12 montículos dispostos em círculo em uma área de aproximadamente um hectare (Figura 4). Este contexto tem datas muito seguras por volta do século VII de nossa era, porém também foram datadas amostras dos séculos IV e V DC, que ainda devem ser vistas com cautela.

As ocupações da fase Paredão estão 
associadas a mudanças tecnológicas significativas verificadas no registro arqueológico regional. $\mathrm{Na}$ cerâmica pode ser percebida uma significativa melhora na escolha das argilas, o que proporciona a confecção de vasos muito grandes e com paredes muito finas. Uma gama muito variada de antiplásticos como cauixi, caraipé, carvão, caco moído, são identificados individualmente ou associados na pasta das cerâmicas. A tecnologia de queima demonstra melhora significativa com alguns exemplares apresentando aspecto próximo ao da vitrificação. Outra particularidade considerável é a construção dos montículos artificiais.

As mudanças tecnológicas parecem culminar em uma rápida expansão da ocupação. Das pequenas aldeias como no sítio Antônio Galo passamos a sítios de grande porte como Açutuba (Heckenberger et al. 1999), Hatahara (Tamanaha \& Rapp Py-Daniel 2009), Laguinho (Castro 2009). O próprio sítio Antônio Galo parece sofrer um processo rápido de expansão, passando para uma área total de aproximadamente 16 hectares (Figura 4).

Desde as pesquisas de Hilbert (1968) é sabido que o processo de formação de terra preta na área de confluência se iniciou em ocupações anteriores, mas é na fase Paredão que identificamos os sítios com maior área e profundidade de ocorrência. Na área central do sítio Hatahara, a camada de terra preta pode chegar a mais de 2 metros de profundidade (Machado 2005, Tamanaha \& Rapp Py-Daniel 2009). No sítio Laguinho, ela chega a $270 \mathrm{~cm}$ (Castro 2009).

Apesar das mudanças consideráveis apontadas anteriormente, ocupações da fase Paredão mostram também características das ocupações anteriores. $\mathrm{Na}$ fase Manacapuru, há também evidência de aldeias construídas em disposição circular na primeira metade do século VII DC (Chirinos 2007; Neves et al. 2004). Alguns elementos da cerâmica como os apliques modelados e a forma de alguns vasos, como o vaso que tem forma semelhante à de canoas (Figura 3) estão presentes também nas cerâmicas Manacapuru e Axinim.

O estado das pesquisas ainda não permite uma correlação direta entre as ocupações das fases Paredão e Axinim. Porém, apesar dos sítios da fase Paredão estarem implantados principalmente nas proximidades da confluência dos rios Negro e Solimões, as cerâmicas Axinim do rio Madeira apresentam traços muito semelhantes ao conjunto Paredão. Ainda fica difícil saber se essa semelhança se deve a uma possível origem comum ou se é decorrente de contatos. De qualquer modo, embora as datas para o início da fase Axinim sejam mais antigas, ocupações Paredão e Axinim são encontradas na ampla área que engloba o Médio/ Baixo rio Madeira, o rio Amazonas e o baixo rio Negro por volta do ano mil da era Cristã. Tudo leva a crer que, mesmo se tratando de um contexto regional multiétnico, até o século IX houve certa estabilidade na ocupação da região.

Os dados atualmente disponíveis mostram que, por volta do ano mil da era Cristã, tanto na região do médio rio Amazonas (Neves 2010), quanto no baixo rio Madeira, se produziram as ocupações com os maiores sítios arqueológicos encontrados até o momento na 


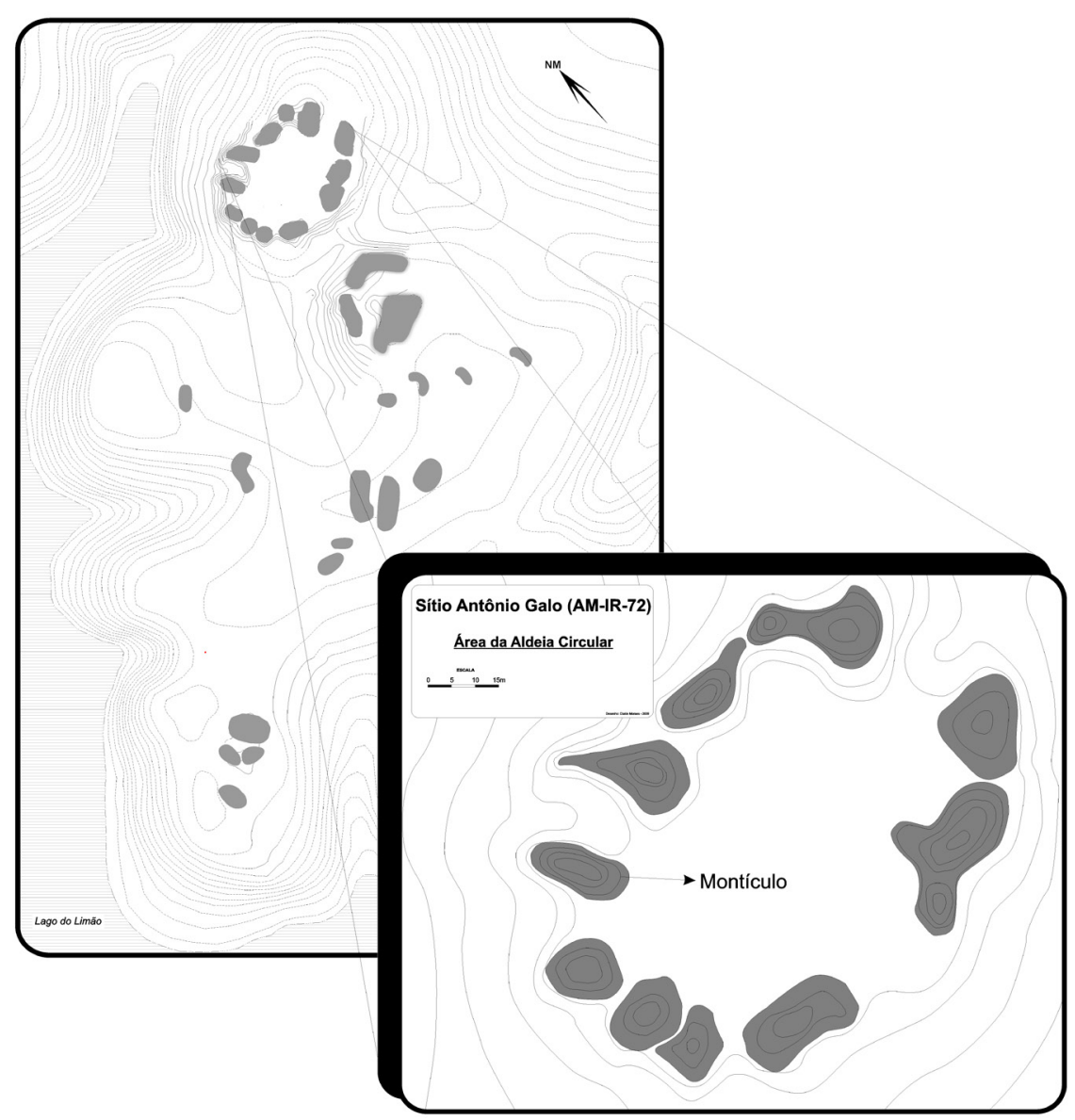

Figura 4 - Sítio Antônio Galo, com área da aldeia circular em destaque. Autoria: Marcos Castro com inclusões e adaptações de Claide Moraes.

Amazônia Central. Nas proximidades de Manaus, sítios como Açutuba, Hatahara, Nova Cidade (Lima 2008), apesar de apresentarem componentes de ocupações anteriores, têm durante a fase Paredão depósitos mais espessos e maior área de dispersão de vestígios.

Nesse mesmo momento, na região do rio Madeira, sítios como Vila Gomes, Borba, Caiçara e São Félix do Aripuanã apresentam áreas muito grandes (Figura
1), o último com área estimada em mais de 80 hectares. O sítio Vila Gomes teve a mancha de ocorrência de terra preta delimitada em 40 hectares.

\section{AS OCUPAÇÕES POLÍCROMAS}

Durante esse período de apogeu demográfico surgiram na região os primeiros sítios com cerâmicas da fase Guarita da tradição Polícroma². As da- 
tas mais antigas até o momento foram obtidas em distintos locais: 900 DC no sítio Açutuba, na margem direita do rio Negro em Iranduba/AM (Heckenberger et al. 1998:9), 880 DC no baixo rio Negro, próximo à foz do rio Branco (Simões \& Kalkmann 1987) e também 880 DC no rio Urucu, já na bacia do rio Solimões (Tamanaha 2012).

Sítios da fase Guarita e complexos similares têm uma ampla dispersão pela Amazônia ocidental. Cerâmicas polícromas muito semelhantes são encontradas desde o médio rio Madeira e baixo rio Amazonas, nas proximidades da atual fronteira dos estados do Amazonas e Pará, até o rio Napo, no Equador. Porém, parece ter havido uma expansão muito rápida desses grupos e os estratos das ocupações são quase sempre superficiais. É muito comum encontrar as ocupações Guarita no final da sequência de sítios com grandes extensões de terra preta formadas em ocupações anteriores. É possível que a fertilidade da terra preta formada nas ocupações anteriores e as concentrações de espécies botânicas úteis que ali se desenvolveram como resultados dessas ocupações tenham sido um grande atrativo para essas reocupações (Junqueira 2008).

O contexto arqueológico do médio rio Amazonas (rio Solimões) apresenta uma extensiva ocupação caracterizada pelas cerâmicas polícromas no período próximo do contato com os primeiros europeus (Tamanaha 2012). Tamanaha (2010) vem estudando a tecnologia cerâmica dos sítios desse período para ver possíveis correlações com as províncias definidas pelos cronistas.

Tradicionalmente, a cerâmica é utilizada como o principal vestígio para identificação de diferenças no registro arqueológico da Amazônia. Como descreve Neves (2010), na região do projeto Amazônia Central as fases arqueológicas tem sido bons marcadores de outras dimensões de variabilidade, tais como forma e densidade de ocupação dos assentamentos. Na Amazônia é provável que artefatos cerâmicos decorados tenham sido agentes portadores de informações culturalmente codificadas. A qualidade das argilas amazônicas faz da cerâmica um suporte de comunicação e expressão cultural muito rico. Em vários conjuntos amazônicos temos parafernália cerâmica exclusiva de contextos simbólicos (Schaan 2004; Barreto 2008, 2010; Gomes 2010). Assim, tendo em vista a elaboração da decoração pode-se dizer que a cerâmica Guarita da Amazônia Ocidental traz verdadeiros enredos impressos na decoração. Um indivíduo que vivia na região do rio Madeira no século XIII D. C. certamente saberia interpretar os códigos simbólicos apresentados em cerâmicas encontradas na região do rio Napo da mesma época, dado o rigor e padronização da cerâmica polícroma identificada nessa região (Figura 5).

Acreditamos que a expansão polícroma se deu de maneira muito rápida e que após a ocupação da região esses grupos se mantiveram em contato muito próximo. Pode ser observada uma padronização formal e decorativa do conjunto artefatual com profundidade temporal e espacial impressionantes. 
Existiam códigos comuns impressos na forma e decoração das cerâmicas que eram compartilhados, e provavelmente resignificados, por povos viven- do desde o médio Madeira até a região do rio Napo, no Equador.

Se tomarmos um caminho fluvial, rota mais provável entre esses dois pon-

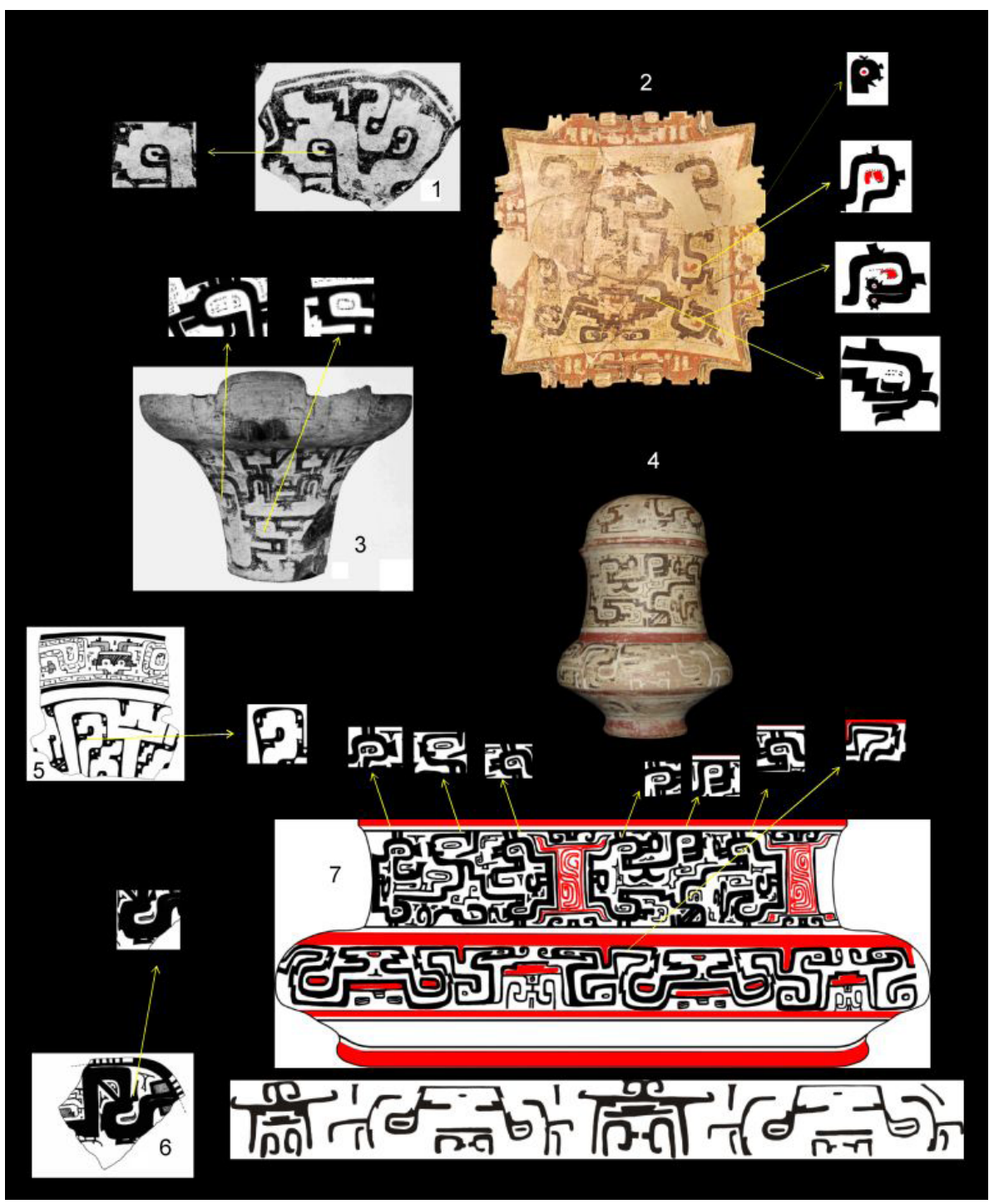

Figura 5 - Cerâmica polícroma da Amazônia Ocidental. 1, 2,3, 5 e 6: cerâmica da fase Napo, Equador. 4 e 7: urna funerária da fase Guarita, baixo Amazonas, motivos pintados e incisos da urna. Em destaque a padronização da decoração com motivos ornitomorfos. Fotomontagem de Claide Moraes; cerâmicas da fase Napo adaptadas de Evans \& Meggers 1968; foto da urna Guarita: Anne Rapp Py-Daniel. 
tos, temos uma distância aproximada de $3.500 \mathrm{~km}$. Ambos os pólos desse trecho possuem datas por volta do século XVI DC para sítios arqueológicos com cerâmicas polícromas, o que mostra que toda a região estava ocupada na mesma época, não se tratando de um movimento migratório que abandonou um lugar e seguiu para outro. Para as ocupações Tupi, Noelli (2008) menciona uma estratégia de ocupação muito semelhante.

\section{AS EVIDÊNCIAS DE CONFLITOS}

No período das grandes chefias regionais da Amazônia os diferentes grupos parecem ter alternado momentos de paz e aliança com momentos de conflitos e guerras (Neves \& Petersen 2006). Essa alternância pode ser observada se considerarmos os dados dos cronistas dos séculos XVI e XVII sintetizados por Porro (1995). A calha do Amazonas foi a única região onde essas chefias regionais foram documentas pelos colonizadores europeus (Carvajal 1542[1942], Porro 1995, Ugarte 2009). Os mesmos mencionaram vastas províncias como a de Aparia o Grande (Carvajal 1542 [1942]: 15), provavelmente a província dos Omagua (Porro 1995:48). Além das chefias regionais os cronistas coletaram informações sobre alianças entre chefes para combater inimigos comuns. Por exemplo, Aparia e seus confederados supostamente estavam em constante conflito com seus vizinhos a jusante do rio, os Aisuari da província de Machifaro (Porro 1995:80). A demarcação das províncias descritas pelos cronistas e a mudança das fron- teiras dos territórios entre os séculos XVI e XVII, demonstram a fluidez dos sistemas políticos regionais indígenas do passado na Amazônia Central (Porro 1995).

O registro arqueológico corrobora os dados históricos. Evidências de conflitos na virada do primeiro para o segundo milênio DC puderam ser confirmadas através da escavação de estruturas defensivas em sítios das ocupações Paredão e nas ocupações Axinim (Moraes 2011). Tais estruturas podem ser valas defensivas, como as encontradas nos sítios Lago Grande (Neves 2005, 2008; Donatti 2003), Açutuba (Neves 2008) e Vila Gomes (Moraes 2010) ou então paliçadas, como no caso do sítio Laguinho (Castro 2009; Tamanaha 2010). No sítio Lago Grande, localizado em uma península com mais de 30 metros de altura sobre um lago da várzea do rio Solimões, uma vala artificial foi construída no istmo que conecta a península à terra firme no início do século XI DC, mais de dois séculos após o início da ocupação do sítio. Pouco tempo depois, o sítio foi abandonado (Neves 2008). No sítio Açutuba, também localizado em um barranco com mais de 30 metros de altura, mas dessa vez em relação à planície aluvial do rio Negro, uma vala artificial com mais de 150 metros de extensão foi também escavada na parte do sítio acessível pela terra firme (Neves 2008). No sítio Laguinho, uma paliçada de mais de 40 metros de comprimento, atestada por uma série de manchas alinhadas de buracos de poste, foi construída em uma 


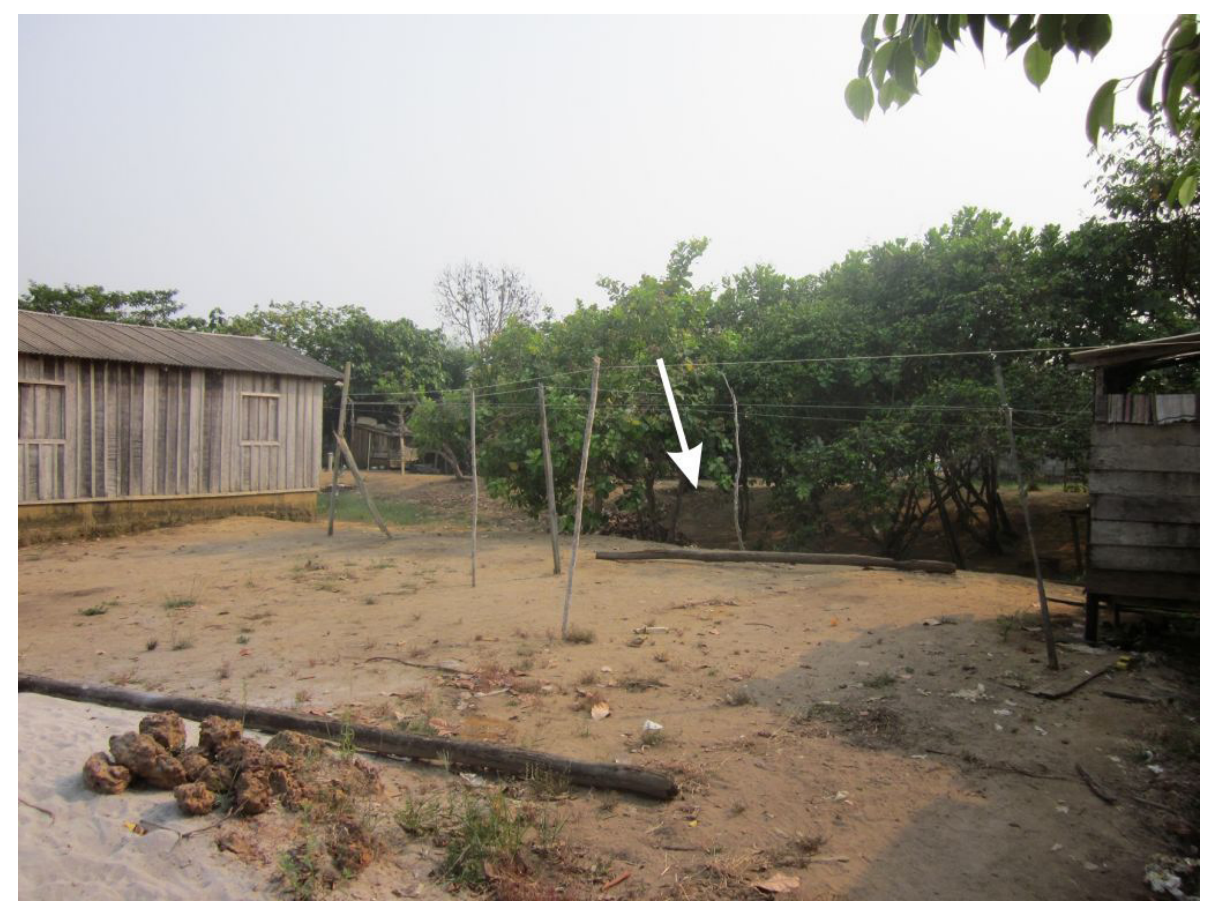

Figura 6 - Quintais do bairro da Colônia em Borba/AM, apresentando partes da vala defensiva do sítio Borba. Foto de Nicolas Kawa

península que separa a parte central do sítio - uma vez mais localizada sobre um barranco alto adjacente à várzea do rio Solimões - da área acessível pela terra firme (Tamanaha 2012).

No baixo rio Madeira, em alguns quintais do bairro da Colônia, na cidade de Borba, sítio Borba (Figura 1), ainda é possível visualizar uma vala defensiva que provavelmente contornava o sítio (Figura 6) (Moraes 2011). Na margem oposta do rio Madeira, no sítio Vila Gomes, identificou-se uma vala artificial que contorna uma área de 20 hectares de terra preta associada a uma ocupação da fase Axinim (Figura 7). A vala se inicia na margem do rio Madeira, avança por cerca de 300 a 400 metros no sentido nordeste para a ter- ra firme, depois segue paralela ao eixo do rio por 325 metros. Na sequência observamos dois pontos sem a continuidade da vala, provavelmente duas entradas para a área protegida, após os quais a vala segue por mais 300 metros, virando novamente para a margem do rio Madeira. No total, a vala possui 1.100 metros de comprimento, com média de 10 a 12 metros de largura e até 3 metros de profundidade (Figura 7).

A escavação de uma trincheira cortando a vala para verificar a estratigrafia e o processo construtivo mostrou a presença de solo amarelo mosqueado com a terra preta, indicando a inversão de camadas típica da construção de uma vala artificial. Entre 10 e 50 centímetros o solo escavado é bem amarelo 
e são raros os fragmentos de cerâmica. É também notável a compactação extrema do solo, como se fosse uma área de trânsito intenso, porém não existem caminhos atuais de passagem de pedestres e tampouco há na memória dos moradores atuais registro desse tipo de uso. É, portanto, provável que a compactação deve ser associada ao período de ocupação pré-colonial do sítio, podendo ser o resultado do trânsito constante no entorno da fortificação. É importante notar que os primeiros 10 $\mathrm{cm}$ escavados não apresentaram tanta compactação.

Entre 50 e $80 \mathrm{~cm}$ de profundidade há uma camada de terra preta selada pelo pacote de solo amarelo depositado durante a construção da vala (Figura 8). Nesta camada, que corresponde à própria camada de ocupação associada à fase Axinim, a quantidade de fragmentos de cerâmica foi bem maior que a vista nos níveis anteriores. A camada continua extremamente compactada. A partir de $80 \mathrm{~cm}$ de profundidade volta a aparecer o solo amarelo enquanto que os fragmentos de cerâmica praticamente desaparecem. No perfil da escavação, que chegou a $110 \mathrm{~cm}$ de profundidade, pode-se constatar que abaixo da base da camada de terra preta o solo é um pouco menos compactado. No total, escavou-se uma trincheira de $11 \mathrm{~m}$ de comprimento, o que permitiu obter uma boa amostra da forma e tamanho da vala.

A estratigrafia da vala e as datas da ocupação do sítio corroboram a hipótese de desestabilidade na região

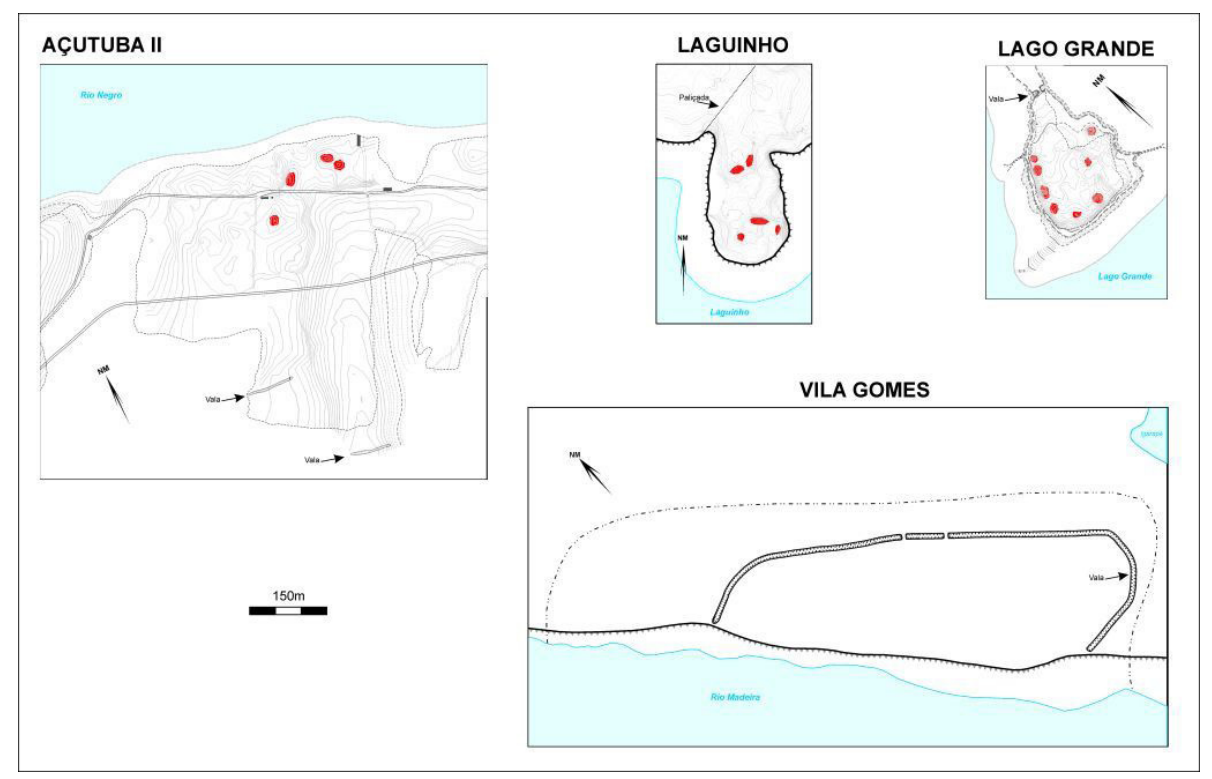

Figura 7 - Sítios arqueológicos pesquisados no Projeto Amazônia Central apresentando valas defensivas e paliçadas. Mapas dos sítios Açutuba II, Laguinho e Lago Grande por Marcos Castro. Mapa do sítio Vila Gomes e adaptações finais da figura por Claide Moraes. 


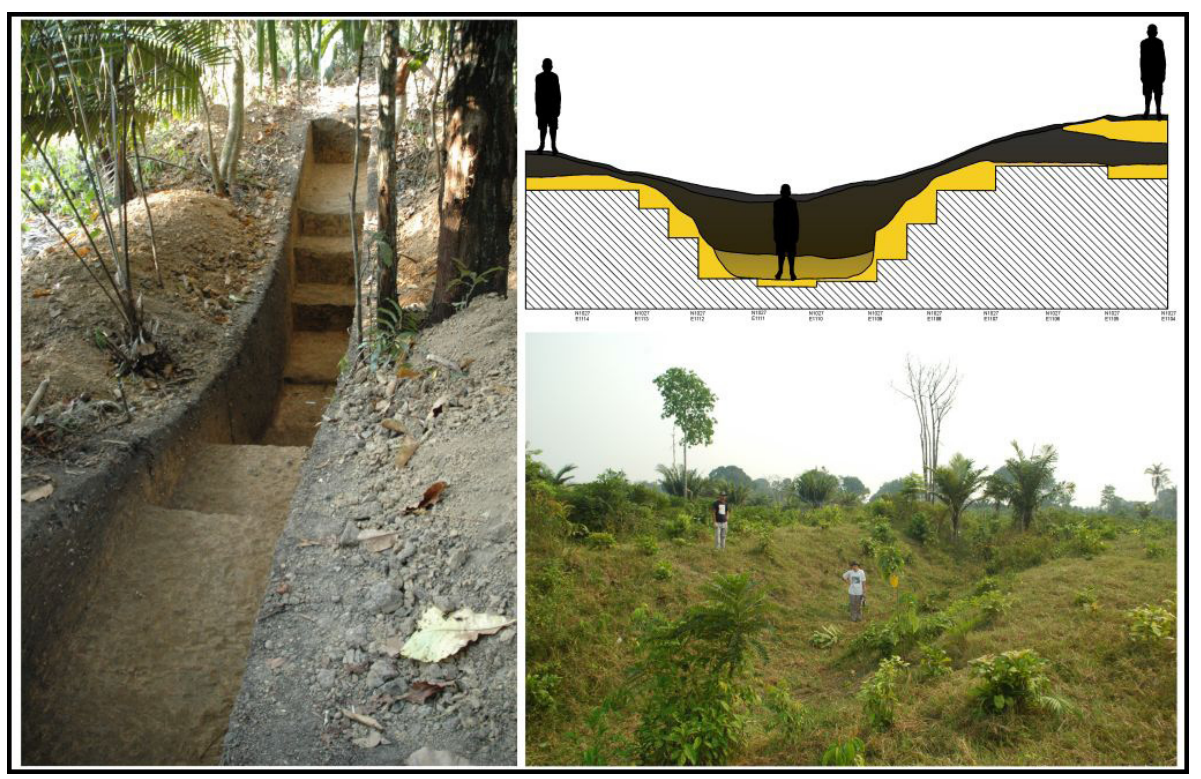

Figura 8 - Vala defensiva do sítio Vila Gomes. Fotografias da trincheira escavada, demonstração da profundidade e croqui do perfil da trincheira. Por Claide Moraes.

por volta do primeiro milênio da era Cristã. Foram datadas duas amostras de carvão coletadas na escavação que realizamos na vala e duas amostras de materiais em contexto na estratigrafia da ocupação do sítio. Como mostra a estratigrafia, quando a vala foi construída já havia formação de terra preta no sítio arqueológico. Conforme ficou evidente na escavação que fizemos na vala, uma camada de cerca de 30 centímetros de terra preta foi lacrada pelo solo amarelo depositado durante a construção da vala. A amostra Beta 297127 (Tabela 1) foi coletada na camada de terra preta lacrada. Portanto, ela é de um período anterior à construção da vala. A amostra Beta 297128 (Tabela 1) é um fragmento de carvão coletado na parte mais profunda da vala. Consequentemente uma data posterior à construção da vala.
As amostras de materiais datados nas camadas de ocupação do sítio mostram que o mesmo foi ocupado por volta do início da era Cristã (Tabela 1). O mapemento do sítio demonstrou que a área de terra preta é de cerca de 40 hectares. A emergência de conflitos na região leva à uma reconfiguração do espaço ocupado. Por volta do ano mil a construção da vala delimita uma área de 20 hectares.

Desta maneira os resultados apontam o evento de construção da vala em algum ponto do intervalo entre a segunda metade do século X e a primeira metade do século XIII. A área do sítio protegida pela vala é reduzida para 20 hectares. Como apontam os dados esse é o período da expansão da ocupação Guarita. As evidências de sitemas defensivos de outros sítios como Lago Grande, Açutuba e Laguinho (Figura 7) também datam desse período. 
Tabela 1

Datações do sítio Vila Gomes, Borba/AM

\begin{tabular}{|c|c|c|c|c|c|}
\hline $\begin{array}{c}\text { Número de } \\
\text { Proveniêncial }\end{array}$ & $\begin{array}{c}\text { Número do } \\
\text { Laboratório }\end{array}$ & Profundidade & $\begin{array}{c}\text { Tipo de } \\
\text { Material }\end{array}$ & $\begin{array}{c}\text { Data Radiocarbônica } \\
\text { Convencional }\end{array}$ & $\begin{array}{c}\text { Data } \\
\text { Calibrada }\end{array}$ \\
\hline Vg204 & Beta-297125 & $30 \mathrm{~cm}$ & Cerâmica & $1330 \pm 50$ AP & 1280 AP \\
\hline Vg220 & Beta-297126 & $118 \mathrm{~cm}$ & Cerâmica & $1910 \pm 40$ AP & 1870 AP \\
\hline Vg255 & Beta-297127 & $60 \mathrm{~cm}$ & Carvão & $1090 \pm 30$ AP & 970 AP \\
\hline Vg272 & Beta-297128 & $110 \mathrm{~cm}$ & Carvão & $890 \pm 30$ AP & 790 AP \\
\hline
\end{tabular}

Na transcrição de Medina, no relato de Carvajal, é mencionada, logo abaixo da passagem pelo rio Negro, a existência de povoações muito grandes e uma delas fortificada com uma muralha de madeiras muito grossas (Carvajal 1542[1942]: 39). No final do século XVII Betendorf (citado em Nimuendajú 2004:167) menciona a existência de aldeias fortificadas entre os índios Arawakí do rio Urubu, no baixo Amazonas. Alfred Métraux documenta estruturas semelhantes nas aldeias dos índios Baure na Bolívia. "Baure villages were surrounded by palisades with loopholes for archers, and a ditch; for further protection pitfalls were concealed in the paths" (Métraux 1942:63).

Os dados obtidos em campo no sítio Vila Gomes permitem que se façam algumas inferências sobre tempo necessário para escavação da vala. Convertendo os $9 \mathrm{~m}^{2}$ escavados em metros cúbicos de terra retirada, chega-se a um total de 7,9 $\mathrm{m}^{3}$ escavados por três indivíduos trabalhando por 8 horas, de maneira exaustiva por cerca de um dia e meio, o que resulta em uma média de 1,5 metros cúbicos escavados por indivíduo/dia. Tomando como média de dimensão a área escavada (com a erosão atual existem pontos da vala mais rasos e mais profundos que o local escavado) o total de metros cúbicos de terra retirados em toda a vala durante o processo construtivo seria de aproximadamente 10.000. Portanto, três indivíduos, utilizando ferramentas modernas e trabalhando 8 horas por dia, demorariam 6,08 anos para cavar a vala.

Castro, em seu trabalho de mestrado, tentando fazer algumas estimativas de mão-de-obra empregada para a construção de montículos com terra e cerâmica, propôs, nas estimativas mais ousadas, que 100 indivíduos gastariam 39,6 dias para construir um montículo de 1.320 $\mathrm{m}^{3}$, caso adicionassem, após um dia de trabalho levando pequenas porções de material, uma tonelada cada um (Castro 2009:101-102). Transportando as estimativas de Castro para o nosso contexto, 100 indivíduos gastariam 303 dias para construir a vala, ou 1.000 indivíduos gastariam 30 dias para realizar a obra.

Assim como Castro apontou em seu trabalho, estas estimativas estão longe de ser um produto fiel à realidade. Não conhecemos as ferramentas, o ritmo de trabalho, as condições físicas, nem tampouco a força da mão-de-obra dos responsáveis pela construção da vala. 
Porém, mesmo que as estimativas estejam fora da realidade, é indiscutível que um grande contingente de indivíduos teve que ser mobilizado para executar a construção da vala. Se a vala foi de fato uma estrutura defensiva, como aqui proposto, é provável que tenha sido construída rapidamente, em um evento único. Não existem evidências de abandono do sítio e reocupação depois da construção da vala. Ao que tudo indica, um grupo que ocupava uma área de aproximadamente 40 hectares teve que se comprimir na metade do espaço e fortificar os limites do assentamento. O sítio continuou unicomponencial até o momento de seu abandono, não tendo sido reocupado por outros grupos, ao contrário dos sítios com estruturas defensivas, como o sítio Borba e os da área de confluência dos rios $\mathrm{Ne}$ gro e Solimões, onde nas camadas superficiais estão presentes vestígios da ocupação Polícroma. Acreditamos que para isso a vala deve ter sido construída em um curto espaço de tempo, mobilizando, inevitavelmente, um grande número de indivíduos.

\section{CONSIDERAÇÕES FINAIS}

O sítio Vila Gomes tem um contexto chave para o entendimento da história pré-colonial da região. Trata de um sítio unicomponencial de grandes proporções, fortificado por uma vala defensiva, com cerâmica da fase Axinim que aparece também em vários sítios na calha do rio Madeira, mas que não é a predominante na região por volta do primeiro milênio da era Cristã. Como constatado no levantamento arque- ológico realizado, a predominância é de sítios associados às ocupações com cerâmicas polícromas.

Com base na padronização rigorosa que identificamos nos códigos simbólicos impressos nas cerâmicas Guarita acreditamos serem válidas as informações dos cronistas sobre a existência de províncias regionais com poder centralizado. Esses dados e as informações levantadas por Porro (1995) sobre a fluidez das fronteiras das chefias regionais nos levam inclusive a pensar que, em períodos anteriores ao contato com os europeus, as sociedades de povos produtores da cerâmica Polícroma poderiam ter uma configuração bem diferente da documentada pelos europeus no início do século XVI DC.

Em 1542, Orellana encontra no caminho entre o rio Madeira e o rio Napo a província de Machifaro, supostos inimigos do senhorio de Aparia, o grande. As semelhanças da cerâmica Guarita com as descrições de Carvajal sobre a cerâmica da "Aldeia da Louça," a jusante da atual cidade de Coari, e a relação cronológica que as mesmas carregam nos levam a pensar que em um determinado momento o trecho pode ter sido dominado por um único grande chefe regional ou por grandes chefes que possuíam alianças.

Como bem demonstram as pesquisas mais recentes da arqueologia Amazônica (Hornborg 2005; Heckenberger 2005, 2010; Neves 2008; Barreto 2008, 2010), as sociedades complexas da Amazônia antiga parecem ser o resultado de estruturas político-regionais multiétnicas. Nosso trabalho vem demonstrando que 
apesar de mudanças significativas no conjunto cerâmico, por volta do ano mil da era Cristã aparecem na região sítios da fase Paredão, Manacapuru, Axinim e Guarita. Na fase Paredão as aldeias circulares puderam ser claramente constatadas (Donatti 2003; Moraes 2006, 2010). Enquanto que nas ocupações Guarita os assentamentos parecem ter disposição linear ao longo do barranco do rio (Rebellato 2007).

Nas fases Paredão e Axinim estão manifestos os sítios maiores e mais densos do registro arqueológico da Amazônia Central. O contexto do ano 1.000 DC parece demonstrar um exemplo claro de relações multiétnicas na Amazônia Central. Pela profundidade da correlação cronológica dessas diferentes manifestações cerâmicas na mesma região, acreditamos que a proposta de Neves \& Petersen (2006) de alternância de momentos de conflitos com momentos de união, inclusive multiétnicas, seja bem plausível. Porém, a chegada das ocupações da fase Guarita na região desestabiliza o contexto político regional. Por volta do século XIII o registro arqueológico aponta para uma hegemonia completa das ocupações polícromas entre o rio Madeira e o rio Napo. Resta ainda compreender quais eram as formas de organização política dessas sociedades.

O rio Madeira é o maior tributário do rio Amazonas, é também um rio que nasce nos Andes. Diante do que estamos observando na cerâmica encontrada no baixo rio Madeira, temos a tendência a acreditar que na pluralidade contida no conjunto cerâmico
Axinim, estaria um "coração cultural" irradiando influências por toda a bacia Amazônica (Latrap 1970; Brochado 1984; Lathrap \& Oliver 1987). As datas antigas para sítios cerâmicos produzidas pelo PRONAPABA, ainda que tidas com ressalvas, como sugere Miller, levam a crer que não podemos descartar totalmente o modelo cardíaco de Lathrap. Sítios como Nova Olinda (Figura 2) apresentam uma sequência cronológica muito coesa para não serem levados em consideração.

A cerâmica Paredão desaparece por volta do século XII, porém continuam existindo ocupações Konduri no baixo Amazonas. Com um melhor quadro da cronologia da região do rio Madeira, já é possível perceber que as estruturas defensivas que estamos estudando no Madeira datam do mesmo período das encontradas na fase Paredão na Amazônia Central. Os traços semelhantes entre a cerâmica Axinim com as cerâmicas mais antigas da Amazônia Central e também com a fase Paredão, mostram que estamos diante de um contexto de continuidade no longo prazo das formas de ocupação no cenário regional. As fases Paredão e Konduri carregam traços já identificados no conjunto cerâmico mais antigo visto no sítio Vila Gomes. Pela grande presença de sítios polícromos na região, acreditamos que as evidências de conflitos identificadas no sítio Vila Gomes estão relacionadas com o aparecimento de grupos produtores de cerâmica polícroma na região. 


\section{AGRADECIMENTOS}

À Fundação de Amparo à Pesquisa do Estado de São Paulo - FAPESP pelo financiamento das pesquisas de campo e laboratório. Aos alunos da turma de arqueologia da UEA pela ajuda no campo em Iranduba. À família Gomes (Vila Gomes - Borba) pela hospitalidade e auxílio no campo. Aos alunos, bolsistas e voluntários do ICS/UFOPA pela ajuda no laboratório. Aos colegas do PAC pela produtiva convivência e aprendizado. À Anne Rapp Py-Daniel pela leitura e comentários sobre as primeiras versões do texto. À Denise Schaan pelo convite em escrever este artigo.

\section{NOTAS}

${ }^{1}$ A ocupação pré-colonial tardia da região do rio Trombetas não está associada à tradição Policroma, e sim à tradição Incisa e Ponteada, mas as cerâmicas Pocó encontradas sob tais ocupações têm uma grande semelhança com as cerâmicas Açutuba e Caiambé dos rios Negro, Solimões e Japurá (Hilbert 1968, Neves 2006).

2 Neste trabalho estamos considerando cerâmica Guarita uma série de conjuntos cerâmicos semelhantes, que foram classificados por diferentes autores, no Brasil, Colômbia, Equador e Peru, como pertencentes às sub-tradições Guarita e Jatuarana, fases Tefé, Nofurei, Napo, Caimito Guarita, além de diversas outras fases regionais.

\section{REFERÊNCIAS}

Arroyo-Kalin, M. 2008. Steps towards an ecology of landscape: a geoarchaeological approach to the study of anthropogenic dark earths in the central Amazon region, Brazil. Tese de Doutorado, Department of Archaeology, University of Cambridge, Cambridge.

Barreto, C. N. G. 2008. Meios místicos de reprodução social: Arte e estilo na cerâmica fu- nerária da Amazônia antiga. Tese de Doutorado, Museu de Arqueologia e Etnologia, Universidade de São Paulo, São Paulo, Brasil.

2010. Cerâmica e complexidade social na Amazônia antiga: Uma perspectiva a partir de Marajó, in Arqueologia Amazônica vol. 1. Organizado por E. Pereira e V. Guapindaia, pp. 193-212. Belém: MPEG/ IPHAN/ SECULT.

Brochado, J. 1984. An ecological model of the spread of pottery and agriculture into eastern South America. Tese de Doutorado, Department of Anthropology, University of Illinois, Illinois.

Carneiro, R. 1971. Review of D. Lathrap, The Upper Amazon. American Journal of Archaeology, 75:237-39.

Carvajal, G. 1542 [1942]. Relación del nuevo descubrimiento del famoso Río Grande que descubrió por muy gran ventura el Capitán Francisco de Orellana. Traduzido por Oviedo e Medina e por Raul Reyes y Reyes. Quito: Biblioteca Amazonas I.

Castro, M. W. 2009. A cronologia dos sítios Lago do Iranduba e Laguinho à luz das hipóteses da ocupação humana para a Amazônia Central. Dissertação de Mestrado, Museu de Arqueologia e Etnologia, Universidade de São Paulo, São Paulo.

Chirinos, R. P. 2007. Padrões de assentamento no sítio Osvaldo, Iranduba, Amazonas. Dissertação de Mestrado, Museu de Arqueologia e Etnologia, Universidade de São Paulo, São Paulo.

Costa, B. L. S. 2011. Boa Esperança e Bom Jesus: $\mathrm{O}$ "universo Borda Incisa" na reserva de desenvolvimento Sustentável Amanã, Estado do Amazonas. Relatório de Qualificação. São Paulo: MAE/USP. Inédito.

Costa, F. W. 2009. Arqueologia das campinaranas do baixo rio Negro: em busca dos pré-ceramistas nos 
areais da Amazônia Central. Tese de Doutorado, Museu de Arqueologia e Etnologia, Universidade de São Paulo, São Paulo.

Donatti, P. B. 2003. A ocupação pré-colonial da área do lago grande, Iranduba, AM. Dissertação de Mestrado, Museu de Arqueologia e Etnologia, Universidade de São Paulo, São Paulo.

Evans, C. \& B. Meggers. 1968. Archaeological Investigations on the rio Napo, Eastern Ecuador. Smithsonian Contributions to Anthropology, vol. 6. Washington, DC: Smithsonian Institution Press.

Frazer, J. A. 2009. Amazonian dark earths and caboclo subsistence on the middle Madeira river, Brazil. Tese de Doutorado, University of Sussex, U.K.

Gomes, D. M. C. 2010. Os contextos e os significados da arte cerâmica dos Tapajó, in Arqueologia Amazônica vol. 1. Editado por E. Pereira \& V. Guapindaia, pp. 213234. Belém, MPEG/ IPHAN/ SECULT.

Guapindaia, V. L. C. 2008. Além da margem do rio - a ocupação Konduri e Pocó na região de Porto Trombetas, PA. Tese de Doutorado, Museu de Arqueologia e Etnologia, Universidade de São Paulo, São Paulo.

Heckenberger, M. J. 2002 Rethinking the Arawakan diaspora: hierarchy, regionality and the Amazonian formative, in Comparative Arawakan bistories: rethinking language family and culture area in Amazonia. Editado por J. Hill \& F. Santos Granero, pp. 99-122. Urbana: University of Illinois Press.

2005. The ecology of power: Culture, place, and personhood in the southern Amazon, A.D. 1000-2000. New York: Routledge.

2010. Archaeology and cultural memory in Amazonia, in Arqueologia Amazônica vol. 2. Editado por E. Pereira \& V. Guapindaia, pp. 519-544. Belém: MPEG/ IPHAN/ SECULT.
Heckenberger, M. J., E. G. Neves \& J. B. Petersen. 1998. De onde surgem os modelos?: Considerações sobre a origem e expansão dos Tupi. Revista de Antropologia 41:69-96.

Heckenberger, M. J., J. B. Petersen \& E. G. Neves. 1999. Village size and permanence in Amazonia: two archaeological examples from Brazil. Latin American Antiquity 10(4):353-376.

Hilbert, P. P. 1955. A Cerâmica Arqueológica da Região de Oriximiná. Belém: Instituto de Antropologia e Etnologia do Pará. Publicação n. 9.

1968. Archäologische Untersuchungen am mittleren Amazonas: Beiträge zur Vorgeschichte des südamerikanischen Tieflandes. Mit 164 Abbildungen und 11 Karten (vom Verfasser). Berlin: Marburger Studien zur Völkerkunde; Bd. 1. Reimer.

Hilbert, P. \& K. Hilbert. 1980. Resultados preliminares de pesquisa arqueológica nos rios Nhamundá e Trombetas, baixo Amazonas. Boletim do Museu Paraense Emilio Goeldi 75:1-11.

Hornborg, A. 2005. Ethnogenesis, regional integration, and ecology in prehistoric Amazonia: Towards a system perspective. Current Anthropology 46(4): 589-620.

Junqueira, A. B. 2008. Uso e manejo da vegetação secundária sobre terra preta por comunidades tradicionais na região do médio rio Madeira, Amazonas, Brasil. Dissertação de Mestrado, INPA, Manaus.

Kawa, N. C. 2008. Use and management of amazonian dark earth in Borba, Amazonas, Brazil. Dissertação de Mestrado, Department of Anthropology, University of Florida.

Lathrap, D. W. 1970. The upper Amazon. Ancient peoples and places. Southampton, Thames \& Hudson.

Lathrap, D. \& J. Oliver. 1987. Aguerito: el complejo policromo mas antiguo de Ameri- 
ca en la confluencia del Apure y el Orinoco (Venezuela). Interciencia 12:274-289.

Lima, H. P. 2008. História das Caretas: a tradição Borda Incisa na Amazônia Central. Tese de Doutorado, Museu de Arqueologia e Etnologia, Universidade de São Paulo, São Paulo.

2010. A "longue dureé" e uma antiga história na Amazônia Central, in Arqueologia Amazônica vol. 2. Editado por E. Pereira \& V. Guapindaia, pp. 605-627. Belém: MPEG/ IPHAN/ SECULT.

Lima, H. P., E. G. Neves \& J. B. Petersen. 2006. La fase Açutuba: Um novo complexo cerâmico na Amazônia Central. Arqueología Suramericana 2(1):26-52.

Machado, J. S. 2005. Montículos artificiais na Amazônia Central: Um estudo de caso do sítio Hatahara. Dissertação de Mestrado, Museu de Arqueologia e Etnologia, Universidade de São Paulo, São Paulo.

Meggers, B. J. 1954. Environmental limitations on the development of culture. American Anthropologist 56(5): 801-824.

1971. Amazonia: man and culture in a counterfeit paradise. Washington: Smithsonian Institution Press.

1990. Reconstrução do comportamento locacional pré-histórico na Amazônia. Boletim do Musen Paraense Emílio Goeldi. Série Antropologia 6(2):183-203.

Meggers, B. J. \& C. Evans.1957. Archeological investigations at the mouth of the Amazon. Smithsonian Institution Bulletin No 167. Bureau of American Ethnology. Washington DC: Smithsonian Institution Press.

1961. An experimental formulation of horizon styles in the tropical forest area of South America, in Essays in pre-columbian art and archaeology. Editado por S. K. Lothrop, pp. 372-388. Cambridge: Harvard University Press.
1983. Lowland South America and the Antilles, in Ancient South America. Editado por J. Jennings, pp. 287-335. San Francisco: W.H. Freeman and Company.

Métraux, A. 1942. The native tribes of Eastern Bolivia and Western Mato Grosso. Bureau of American Ethnology, Bulletin 134. Washington DC: Smithsonian Institution.

Miller, E. T. 1979/1983. Catálogo de sítios arqueológicos do PRONAPABA pesquisados por Miller. Banco de dados. Inédito.

Moraes, C. P. 2006. Arqueologia na Amazônia Central vista de uma perspectiva da região do Lago do Limão. Dissertação de Mestrado, Museu de Arqueologia e Etnologia, Universidade de São Paulo, São Paulo.

2010. Aldeias circulares na Amazônia Central: um contraste entre fase Paredão e fase Guarita, in Arqueologia Amazônica vol. 2. Editado por E. Pereira \& V. Guapindaia, pp. 581-604. Belém: MPEG/ IPHAN/ SECULT.

2011. Arqueologia regional na Amazônia Central: A fase Paredão e sua inserção no contexto pré-colonial Amazônico. Relatório Final FAPESP. São Paulo: MAE/ USP. Inédito.

Neves. E. G. 2005. Warfare in precolonial Amazonia: when Carneiro meets Clastres, in Warfare in cultural context: Practice theory and the archaeology of war. Editado por A. Nielsen \& W. Walker. Tucson: University of Arizona Press.

2008. Ecology, ceramic chronology and distribution, Long-term history, and political change in the Amazonian Floodplain, in Handbook of South American Archaeology. Editado por H. Silvermann \& W. Isbell, pp. 359-379. New York: Springer.

2010. Arqueologia da Amazônia Central e as classificações na Arqueologia Amazônica, in Arqueologia Amazônica vol. 2. Editado por E. Pereira \& V. Guapindaia, 
pp. 561-579. Belém: MPEG/ IPHAN/ SECULT.

2011. Archaeological cultures and past identities in the pre-colonial Central Amazon, in Ethnicity in Ancient Amazonia. Organizado por A. Hornborg, A. \& J. D. Hill, pp. 31-56. Boulder: University Press of Colorado.

Neves, E. G. \& J. B. Petersen. 2006. Political economy and pre-Columbian landscape transformations in Central Amazonia, in Time and complexity in historical ecology: Studies in the neotropical lowlands. Editado por W. Balée \& C. Erickson, pp. 279-309. New York: Columbia University Press.

Neves, E., J. Petersen, R. Bartone \& C. Silva. 2003. Historical and socio-cultural origins of Amazonian dark earths, in Amazonian Dark Earths: Origin, Properties, Management. Editado por J. Lehmann, D. Kern, B. Glaser \& W. Woods, pp. 1-45. Dordrecht: Kluwer Academic Press.

Neves, E. G., J. B. Petersen, R. N. Bartone \& M. J. Heckenberger. 2004. The timing of terra preta formation in the central Amazon: Archaeological data from three sites, in Amazonian dark earths: Explorations in space and time, pp. 125-134 . Editado por B. Glaser \& W. I. Woods. Berlin: Springer Verlag.

Nimuendajú, C. 2004. In pursuit of a past Amazon. Archaeological researches in the Brazilian Guyana and in the Amazon region. Traduzido por $\mathrm{S}$. Rydén \& P. Stenborg. Göteborg: Elanders Infologistik.

Noeli, F. 2008. The Tupi Expansion, in Handbook of South American Archaeology. Editado por H. SIlvermann \& W. Isbell, pp. 658-670. New York: Springer.

Petersen, J., E. Neves \& M. Heckenberger. 2001. Gift from the past: Terra preta and prehistoric Amerindian occupation in Amazonia, in Unknown Amazon, Culture in Nature in Ancient Brazil. Editado por C. McEwan, C.Barreto \& E. Neves, pp. 86-105. London:
British Museum Press.

Porro, A. 1995. O povo das águas: Ensaios de etno-história amazônica. Petrópolis: Vozes; São Paulo: EdUSP.

Rapp Py-Daniel, A. 2009. Arqueologia da morte no sítio Hatahara durante a fase Paredão. Dissertação de Mestrado, Museu de Arqueologia e Etnologia, Universidade de São Paulo, São Paulo.

2010. O que o contexto funerário nos diz sobre populações passadas: o sítio Hatahara, in Arqueologia Amazônica vol. 2. Editado por E. Pereira \& V. Guapindaia, pp. 629653. Belém: MPEG/ IPHAN/ SECULT.

Rebellato, L. 2007. Interpretando a variabilidade cerâmica e as assinaturas químicas e físicas do solo no sítio arqueológico Hatahara. Dissertação de Mestrado, Museu de Arqueologia e Etnologia, Universidade de São Paulo, São Paulo.

Schaan, D. P. 2004. The Camutins chiefdom: Rise and development of complex societies in Marajó Island, Brazilian Amazon. Ph.D. Dissertation, Department of Anthropology, University of Pittsburgh.

SIMÕES, M. F. 1974. Contribuição à arqueologia dos arredores do Baixo Rio Negro, Amazonas. Publicações Avulsas do Museu Paraense Emílio Goeldi 26: 165-188.

Simões, M. F. \& A. Kalkmann. 1987. Pesquisas arqueológicas no médio rio Negro (Amazonas). Revista de Arqueologia 4(1): 83-116.

Simões, M. F. \& Lopes, D. 1987. Pesquisas arqueológicas no baixo/médio Rio Madeira (Amazonas). Revista de Arqueologia 4(1):117-133.

Tamanaha, E. K. 2010. Ocupação polícroma no baixo e médio Solimões, Estado do Amazonas. Relatório de Qualificação. Museu de Arqueologia e Etnologia da Universidade de São Paulo, São Paulo. 
2012. Ocupação polícroma no baixo e médio Solimões, Estado do Amazonas. Dissertação de Mestrado. Museu de Arqueologia e Etnologia da Universidade de São Paulo, São Paulo.

Tamanaha, E. K. \& A. Rapp Py-Daniel. 2009. Sítio Hatahara: estruturas funerárias, residenciais ou ambas? Revista do Museu de Arqueologia e Etnologia 8: 63-73.

Ugarte, A. S. 2009. Sertões de bárbaros: O mundo natural $e$ as sociedades indígenas da Amazônia. Manaus: Editora Valer.

Valle, R. B. M. 2005. Levantamento etnoarqueológico em terras indígenas na bacia Amazônica. Relatório Parcial. Manaus: INPA. Inédito

Valle, R. \& C. P. Moraes. 2007. Relatório arqueológico da RDS do rio Aripuanã/ AM. Manaus: SDS. Inédito.

Recebido em 10/02/2012.

Aprovado em 12/03/2012. 